\title{
Atividade enzimática e perfil da comunidade bacteriana em solo submetido à solarização e biofumigação
}

\author{
Samuel Ribeiro Passos ${ }^{(1)}$, Fábio Bueno dos Reis Junior(2), Norma Gouvêa Rumjanek ${ }^{(3)}$, \\ leda de Carvalho Mendes ${ }^{(2)}$, Miriam Josefina Baptista ${ }^{(4)}$ e Gustavo Ribeiro Xavier ${ }^{(3)}$
}

\begin{abstract}
(1) Universidade Federal Rural do Rio de Janeiro, Departamento de Agronomia e Ciência do Solo, Rodovia BR 465, Km 7, CEP 23890-000 Seropédica, RJ. E-mail: passos.samuel@gmail.com(2)Embrapa Cerrados, BR 020, Km 18, CEP 73310-970 Planaltina, DF. E-mail: fabio@cpac.embrapa.br, mendesi@cpac.embrapa.br (3)Embrapa Agrobiologia, BR 465, Km 7, CEP 23890-000 Seropédica, RJ. E-mail: norma@cnpab.embrapa.br, gustavo@cnpab.embrapa.br (4)Embrapa Hortaliças, BR 060, Km 09, CEP 70359-970 Gama, DF. E-mail: mirian@cnph.embrapa.br
\end{abstract}

Resumo - O objetivo deste trabalho foi avaliar o efeito da solarização e da biofumigação sobre a comunidade microbiana do solo, por meio da atividade da enzima beta-glicosidase e do perfil do 16S rDNA, determinado com PCR-DGGE. A solarização do solo, com cobertura de plástico, foi feita por períodos de dois, quatro e seis meses, e a biofumigação foi realizada pela incorporação de 2 e $5 \%$ (v/v) de cama-de-frango ao solo. Logo após a retirada da cobertura de plástico e aos 30 dias após a remoção, a atividade da beta-glicosidase foi menor em relação ao tratamento não solarizado. Aos 60 dias, não foram mais observadas diferenças entre os tratamentos. A adição de cama-de-frango a 5\% estimulou a atividade da beta-glicosidase. O perfil da estrutura da comunidade bacteriana foi influenciado pelo tempo de solarização, independentemente da época da retirada da cobertura de plástico. Não foi observado efeito da adição de cama-de-frango ao solo, no perfil da comunidade. A solarização afeta a atividade da beta-glicosidase, mas esses efeitos não são mais detectáveis após 60 dias da retirada da cobertura de plástico, diferentemente do que foi observado em relação à estrutura da comunidade bacteriana por PCR-DGGE. A biofumigação estimula a atividade da beta-glicosidase, mas não afeta o perfil da comunidade microbiana.

Termos para indexação: beta-glicosidase, cama-de-frango, diversidade microbiana, ecologia microbiana, manejo do solo, $16 \mathrm{~S}$ rDNA.

\section{Enzymatic activity and bacterial community profile in soil under solarization e biofumigation}

\begin{abstract}
The objective of this work was to evaluate the effects of solarization and biofumigation on the soil microbial communities, by means of beta-glucosidase activity and 16S rDNA PCR-DGGE analyses. Solarization with a plastic covering of the soil took place over two, four and six months, and the soils were biofumigated by the addition of 2 and $5 \%(\mathrm{v} / \mathrm{v})$ of chicken litter to the soil. Right after the plastic cover removal and after 30 days, beta-glucosidase was lower than in the nonsolarizated control. After 60 days, there were no longer significant differences in beta-glucosidase activity between treatments. The addition of $5 \%$ chicken litter stimulated betaglucosidase activity. Bacterial community profile was influenced by solarization time, regardless of time of plastic cover removal. There was no effect of chicken litter amendments over the bacterial community structure. Solarization affects beta-glucosidase activity but, after 60 days, its effects are no longer detectable, differently of the observed data regarding soil bacterial community structure by PCR-DGGE. Biofumigation stimulates beta-glicosidase activity, but it doesn't affect the bacterial community structure.
\end{abstract}

Index terms: beta-glucosidase, chicken litter, microbial diversity, microbial ecology, soil management, $16 \mathrm{~S}$ rDNA.

\section{Introdução}

A solarização e a biofumigação do solo são estratégias de desinfestação que não utilizam produtos químicos, são de uso simples e custo relativamente baixos (Katan \& DeVay, 1991; Souza, 1994; Ghini,
1997; Lazarovits, 2001; Schoenmaker \& Ghini, 2001; Baptista et al., 2007). A solarização do solo baseiase na utilização da energia solar, para o aquecimento do solo úmido coberto com polietileno transparente. A biofumigação é feita pela adição ao solo de compostos orgânicos ricos em nitrogênio ou enxofre 
(Katan et al., 1976; Blok, 2000; Schoenmaker \& Ghini, 2001), cuja decomposição libera gases tóxicos, o que provoca redução de fitopatógenos no solo (Stapleton, 1996, 2000).

Embora essas práticas tenham apresentado eficiência no controle de fitopatógenos do solo (Stapleton \& DeVay, 1984; Kennedy, 1999), pouco tem sido feito para avaliar seus efeitos na microbiota não patogênica. Os resultados disponíveis da utilização dessas técnicas sobre a microbiota podem variar em cada caso, de acordo com o tipo de solo, o patógeno, as culturas utilizadas, o manejo e o ambiente estudado (Mahmoud, 1996; Shukla et al., 2000; Barbour et al., 2002). É importante que estudos sejam realizados com esse enfoque, para melhor entendimento dos efeitos dessas práticas sobre a comunidade microbiana do solo.

As análises de atividade enzimática do solo, assim como de outros atributos biológicos e bioquímicos, têm detectado alterações nos solos pelo seu uso, manejo ou outras influências antrópicas, com maior antecedência do que indicadores químicos e físicos (Matsuoka et al., 2003; Chaer \& Tótola, 2007). A beta-glicosidase é uma enzima que atua na etapa final do processo de decomposição da celulose, pela hidrolisação dos resíduos de celobiose (Tabatabai, 1994), e alterações em sua atividade podem ter, portanto, influência sobre a qualidade do solo. Entre os indicadores avaliados no trabalho de Chaer \& Tótola (2007), a atividade da enzima beta-glicosidase ficou entre os mais sensíveis ao efeito do uso ou manejo do solo, em áreas com eucalipto. Assim, mensurações da atividade da beta-glicosidase, em áreas sob solarização, são potencialmente interessantes.

Com o avanço da biologia molecular, tem sido possível o desenvolvimento de técnicas que não requerem o cultivo de microrganismos, para a caracterização da diversidade taxonômica, funcional e estrutural de comunidades microbianas (Hugenholtz et al., 1998). Métodos baseados no perfil de comunidades, como o de DGGE ("denaturing gradient gel electrophoresis" - eletroforese em gel de gradiente desnaturante) (Muyzer et al., 1998), apresentam vantagens sobre métodos dependentes de cultivos, particularmente no que se refere à fração dominante das comunidades (Wakelin et al., 2008), à capacidade em revelar a dinâmica bacteriana em ambientes naturais (Ferreira et al., 2008) e à possibilidade de se correlacionar diferenças no perfil da comunidade com atributos físicoquímicos e biológicos do solo (Smalla et al., 2007).

O objetivo deste trabalho foi avaliar os efeitos da solarização e biofumigação sobre a estrutura da comunidade bacteriana do solo, por meio da atividade da enzima beta-glicosidase e do perfil do $16 \mathrm{~S}$ rDNA, por PCRDGGE.

\section{Material e Métodos}

$\mathrm{O}$ experimento foi realizado na área experimental da Embrapa Hortaliças, em Brasília, DF, de abril de 2005 a fevereiro de 2006. Os tratamentos foram dispostos em seis blocos $(5 \times 48 \mathrm{~m})$, com parcelas subdivididas, em área total de 30x50 m, naturalmente infestada com a raça 1 , biovar 1, de Ralstonia solanacearum.

Os tratamentos nas parcelas $(5 \times 12 \mathrm{~m})$ foram: solo não solarizado e solarizado por dois, quatro e seis meses; e nas subparcelas $(5 \times 4 \mathrm{~m})$ : adição de cama-de-frango a 0,2 e $5 \%(\mathrm{v} / \mathrm{v})$. O solo foi preparado com aração até $20 \mathrm{~cm}$ de profundidade, uso de subsolador e de enxada rotativa. A biofumigação foi concomitante à solarização. Após a adição da cama-de-frango, foi feita a irrigação até a capacidade de campo e, em seguida, as parcelas a serem solarizadas foram cobertas com folhas de plástico de polietileno transparente de $75 \mu \mathrm{m}$ de espessura (Baptista et al., 2007). Logo após a retirada da cobertura de plástico, toda a área foi plantada com tomate de mesa, híbrido San Vito (Embrapa Hortaliças, 2006).

Para as avaliações da atividade da enzima betaglicosidase, foram retiradas amostras de solo, na profundidade de $0-10 \mathrm{~cm}$, em três momentos diferentes, logo após o término do período de solarização, 30 e 60 dias depois da retirada dos plásticos. A atividade da beta-glicosidase foi estimada de acordo com Tabatabai (1994), por meio da determinação colorimétrica do $p$-nitrofenol, liberado pela enzima, quando o solo é incubado com um substrato específico ( $p$-nitrofenil-betaD-glicopironosídeo).

Em razão das limitações do número de amostras nos géis de DGGE, para a análise do perfil do 16S rDNA, foram avaliadas três amostras compostas, obtidas a partir de duas amostras simples de dois blocos, em cada tratamento. As coletas foram realizadas logo após a retirada das coberturas de plástico, e 60 dias depois, em solo da camada superficial $(0-10 \mathrm{~cm})$. A extração de DNA total do solo foi realizada com o kit Ultra Clean (Mo Bio).

A reação de polimerase em cadeia (PCR) foi dimensionada com volume final de $35 \mu \mathrm{L}$, tendo-se utilizado os iniciadores F968-GC e R1401 (Gelsomino et al., 1999), à concentração de $0,2 \mu \mathrm{M}$ cada, tampão de reação $(10 \mathrm{mM}), \mathrm{MgCl}_{2}(1,5 \mathrm{mM})$, dNTPs $(0,3 \mathrm{mM}$ 
cada), albumina bovina $\left(0,5 \mu \mathrm{g} \mu \mathrm{L}^{-1}\right)$ e Taq DNA polimerase $(1,75 \mathrm{U})$. As condições de amplificação foram: desnaturação inicial de $93^{\circ} \mathrm{C}$ por $5 \mathrm{~min}$, seguida de 35 ciclos com $1 \mathrm{~min}$ a $94^{\circ} \mathrm{C}, 1 \mathrm{~min}$ a $55^{\circ} \mathrm{C}$ e 2 min a $72^{\circ} \mathrm{C}$, seguidos de uma extensão final de $72^{\circ} \mathrm{C}$ por $5 \mathrm{~min}$.

O produto da amplificação foi analisado por DGGE, em gradiente desnaturante de 50 a $70 \%$, com uso do sistema DCode System. Foram utilizados $15 \mu \mathrm{L}$ de DNA amplificado por linha, corante de corrida $(0,5 \%$ azul de bromofenol, $40 \%$ sacarose, $0,1 \mathrm{~mol} \mathrm{~L}^{-1}$ de EDTA, $5 \%$ de SDS), na concentração final de $1 \mathrm{X}$. Como marcador para normalização dos géis, utilizou-se uma amostra formada pela mistura da amplificação do DNA de quatro microrganismos obtidos da Embrapa Agrobiologia Sinorhizobium fredii, Azospirillum brasilense, Burkholderia sp., Rhizobium tropici IIA -, cujas posições de bandas no gel são conhecidas e foram dispostas nas laterais e na parte central dos géis.

Após a eletroforese $\left(120 \mathrm{~V} ; 60^{\circ} \mathrm{C} ; 16\right.$ horas $)$, o gel foi corado com prata, secado e digitalizado, e o dendrograma de similaridade foi gerado pelo programa Gel Compar II, tendo-se utilizado o coeficiente de Jaccard e o método UPGMA, para cada uma das repetições, para se manter a fidelidade das amostras. Ao final, as amostras foram agrupadas pelo programa NTSYS (Rohlf, 1994), a partir de uma matriz binária de ausência e presença de bandas, de acordo com Aboim et al. (2008). Os dados obtidos da atividade da beta-glicosidase foram submetidos à análise de variância, e a comparação de médias foi feita pelo teste de Duncan, a 5\% de probabilidade.

\section{Resultados e Discussão}

Em nenhuma das coletas houve efeito da interação entre a solarização e a adição de cama-de-frango sobre a atividade da enzima beta-glicosidase. Logo após a retirada da cobertura de plástico, foi observado efeito negativo da solarização sobre a atividade da betaglicosidase (Tabela 1). Após 30 dias, esse efeito continuou a ser observado, e o tratamento que permaneceu sob solarização por seis meses foi o mais afetado. Ghini et al. (2002) também observaram o efeito da solarização sobre a atividade enzimática do solo: após três meses de solarização, a atividade microbiana do solo, avaliada por meio da hidrólise de diacetato de fluoresceína (FDA), foi inferior àquela observada no tratamento sem solarização. Okur et al. (1999) mostraram que, após seis semanas de solarização, a atividade da enzima desidrogenase decresceu $55 \%$ em comparação ao solo não solarizado. Esses autores mencionam que, durante a solarização, o aumento da temperatura do solo pode inativar as enzimas, em consequiência da desnaturação das proteínas. Geralmente, o aumento da temperatura do solo, estimulado pela solarização, também resulta na diminuição da biomassa microbiana (Patrício et al., 2006; Baptista et al., 2007), o que pode ser refletido na atividade das enzimas do solo.

Após 60 dias do final da solarização, não se observaram mais diferenças entre o controle não solarizado e os demais tratamentos sobre a atividade da beta-glicosidase (Tabela 1), o que é um indício de recuperação nas propriedades biológicas do solo. Os dados do presente trabalho corroboram os de Baptista et al. (2007), acerca da respiração basal do solo. Esses autores observaram que a solarização afetou negativamente a respiração basal do solo, logo após a retirada da cobertura de plástico, o que não foi observado mais aos 60 dias.

A adição de cama-de-frango estimulou a atividade da beta-glicosidase em todas as coletas (Tabela 1), o que pode ser explicado pela natureza desta enzima, relacionada ao ciclo do carbono. Ghini et al. (2002), ao utilizar lodo de esgoto, cama-de-frango e casca de Pinus, como fontes de matéria orgânica na biofumigação, observaram maior atividade microbiana do solo com a incorporação de cama-de-frango, o que, segundo esses autores, foi motivado pela estreita relação $\mathrm{C} / \mathrm{N}$ associada

Tabela 1. Efeito dos diferentes períodos de solarização e da adição de cama-de-frango para biofumigação do solo, sobre a atividade da enzima beta-glicosidase no solo, imediatamente e após 30 e 60 dias da retirada da cobertura de plástico ${ }^{(1)}$.

\begin{tabular}{|c|c|c|c|}
\hline \multirow[t]{2}{*}{ Tratamento } & \multicolumn{3}{|c|}{$\begin{array}{l}\text { Atividade da beta-glicosidase } \\
\left(\mu \mathrm{g} p \text {-nitrofenol } \mathrm{g}^{-1} \text { solo } \mathrm{h}^{-1}\right)\end{array}$} \\
\hline & Imediatamente & 30 dias & 60 dias \\
\hline & \multicolumn{3}{|c|}{ Solarização } \\
\hline Não solarizado & $122,55 a$ & $145,05 \mathrm{a}$ & 98,51 \\
\hline Solarizado (2 meses) & $94,12 b$ & $117,45 b$ & 92,46 \\
\hline Solarizado (4 meses) & $92,61 b$ & $107,43 b c$ & 89,24 \\
\hline Solarizado (6 meses) & $90,46 b$ & $96,26 c$ & 91,90 \\
\hline \multirow[t]{2}{*}{ CV (\%) } & 9,57 & 18,00 & 8,43 \\
\hline & \multicolumn{3}{|c|}{ Biofumigação } \\
\hline Sem cama-de-frango $(0 \%)$ & $95,19 b$ & $102,97 b$ & $87,57 \mathrm{~b}$ \\
\hline Cama-de-frango (a $2 \%$ ) & $104,58 \mathrm{a}$ & $110,27 b$ & $92,83 b$ \\
\hline Cama-de-frango (a 5\%) & $100,04 \mathrm{ab}$ & $136,41 \mathrm{a}$ & $98,69 a$ \\
\hline $\mathrm{CV}(\%)$ & 9,57 & 18,00 & 8,43 \\
\hline
\end{tabular}

${ }^{(1)}$ Médias seguidas por letras iguais, nas colunas, não diferem entre si pelo teste de Duncan, a $5 \%$ de probabilidade. 
ao alto teor de matéria orgânica desse material. A matéria orgânica também atua para proteger e manter as enzimas do solo em suas formas ativas, pela formação de complexos enzima-compostos húmicos (Deng \& Tabatabai, 1997).
De acordo com o perfil da estrutura da comunidade bacteriana dominante, obtida por meio da utilização da técnica de PCR-DGGE, pôde-se observar agrupamento das amostras de acordo com o tempo de solarização (Figuras 1 e 2). Logo após a retirada da cobertura de

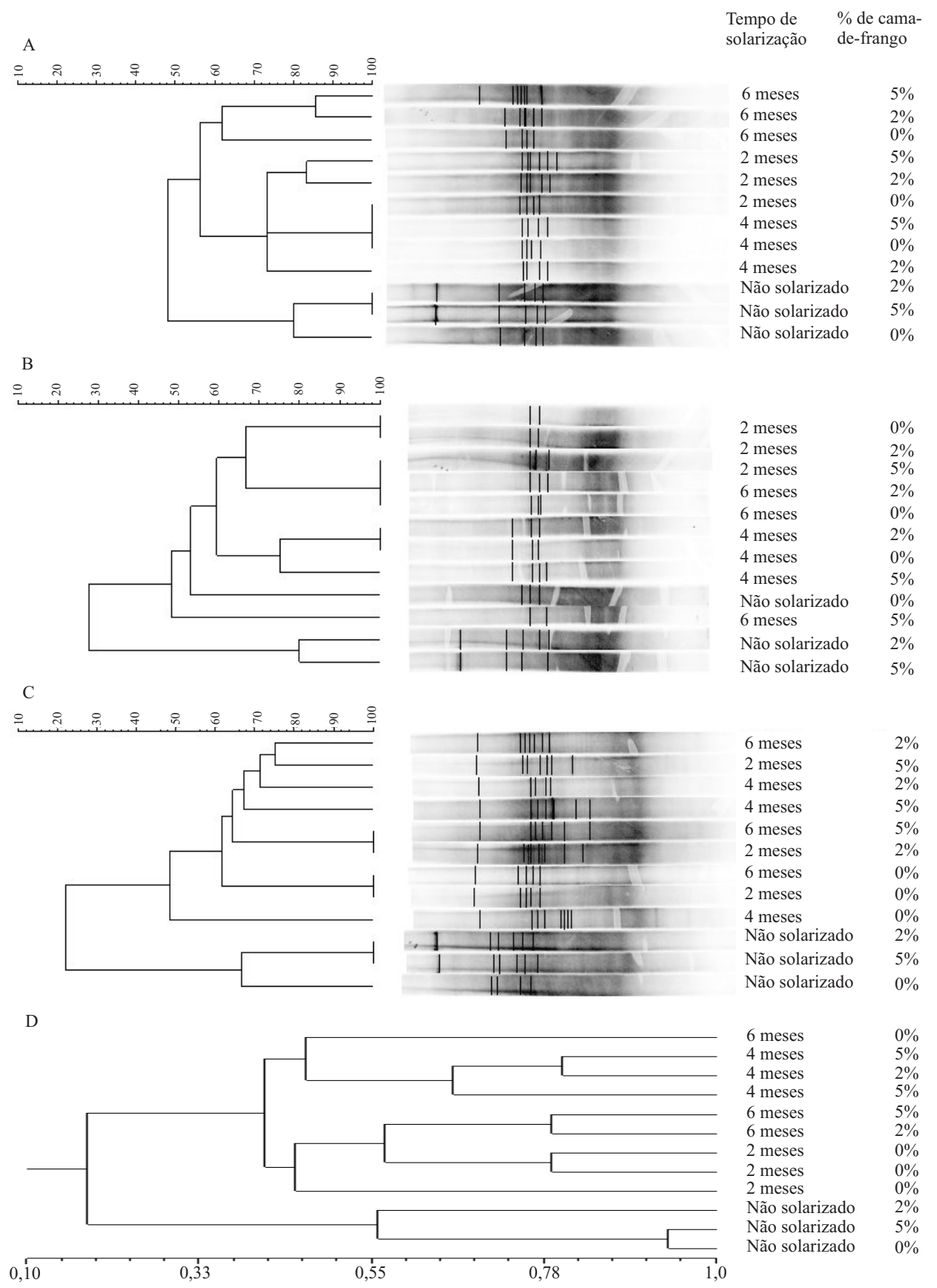

Figura 1. Dendrograma de similaridade do perfil do $16 \mathrm{~S}$ rDNA PCR-DGGE de solo solarizado por 2, 4 e 6 meses ou não solarizado; e de solo biofumigado com 2 e $5 \%$ de cama-de-frango ou sem biofumigação. Os dendrogramas A, B e C representam as repetições 1, 2 e 3, respectivamente; o dendrograma D foi gerado a partir da junção das três repetições, analisadas pelo programa NTSYS. Amostras do solo coletadas logo após a retirada da cobertura de plástico. 
plástico, as amostras dos tratamentos não solarizados foram agrupadas independentemente dos outros tratamentos (Figura 1), o que é um indicativo de alteração na estrutura da comunidade bacteriana. Transcorridos
60 dias, as amostras dos tratamentos não solarizados foram agrupadas com tratamentos de quatro e seis meses de solarização, mas, ainda assim, foi possível observar efeito do tempo de solarização no solo (Figura 2).

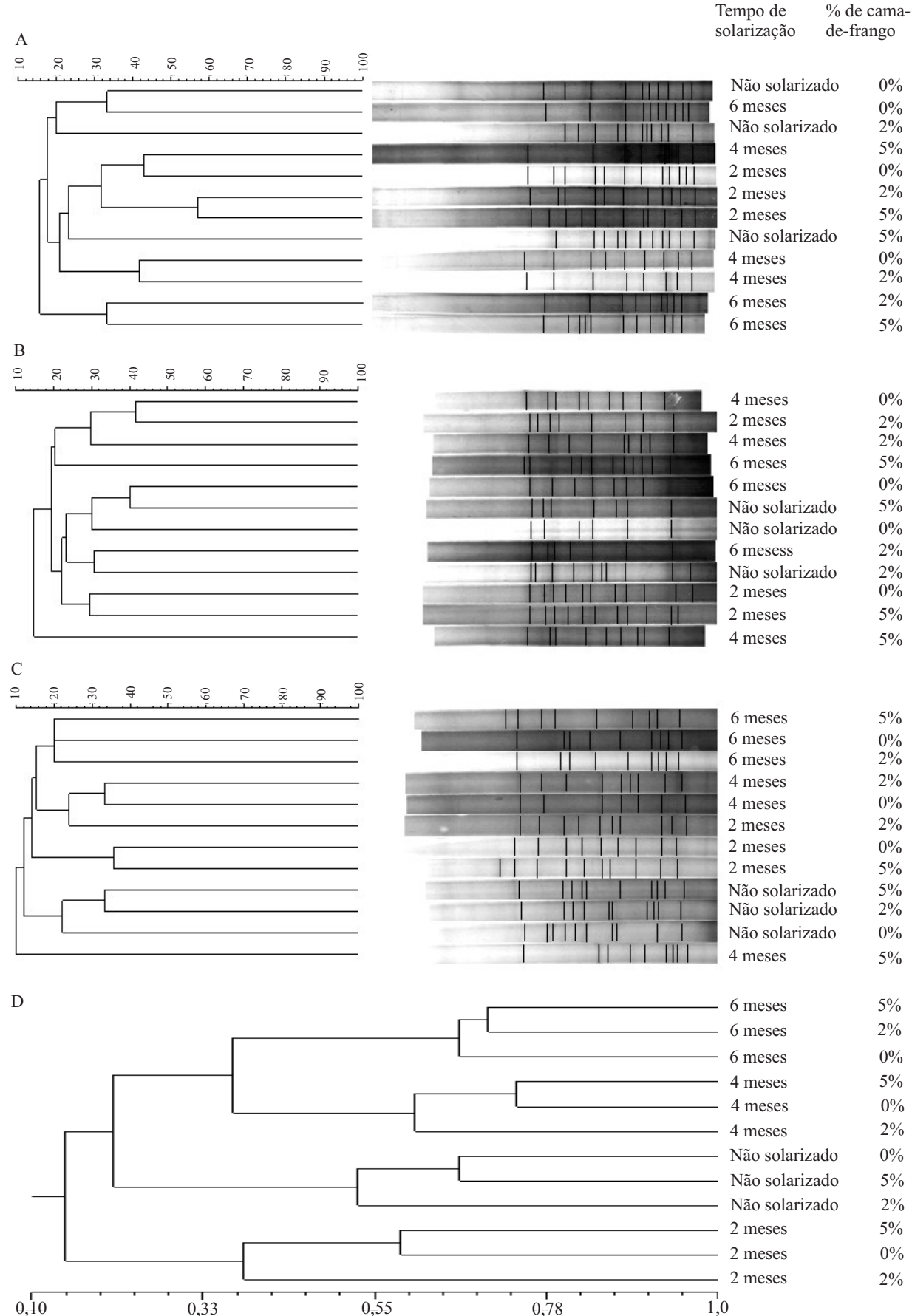

Figura 2. Dendrograma de similaridade do perfil do $16 \mathrm{~S}$ rDNA PCR-DGGE de solo solarizado por 2, 4 e 6 meses ou não solarizado; e de solo biofumigado com 2 e $5 \%$ de cama-de-frango ou sem biofumigação. Os dendrogramas A, B e C representam as repetições 1, 2 e 3, respectivamente; o dendrograma D foi gerado a partir da junção das três repetições, analisadas pelo programa NTSYS. Amostras do solo coletadas 60 dias após a retirada da cobertura de plástico. 
A alteração do perfil do 16S rDNA PCR-DGGE pode ser resultado do efeito direto do tratamento térmico do solo sobre a comunidade microbiana, como também pode ser advindo de alterações nas propriedades físicoquímicas dos habitats ou mesmo de outros fatores ecológicos, tais como competição de espécies bacterianas dominantes, presença de predadores e aumento da disponibilidade de nutrientes (Gelsomino \& Cacco, 2006).

Independentemente da época de coleta, não foi observado agrupamento relacionado aos teores de camade-frango aplicada ao solo no processo de biofumigação, e não houve, portanto, alteração do perfil da estrutura da comunidade bacteriana dominante. Em contraposição a esses resultados, Tiquia et al. (2002) e Schönfeld et al. (2003) observaram que a adição de matéria orgânica apresenta efeito na estrutura dessas comunidades do solo.

\section{Conclusões}

1. A atividade da enzima beta-glicosidase é afetada pela solarização, mas esses efeitos não são mais detectáveis 60 dias após a retirada da cobertura de plástico.

2. O tempo de solarização interfere no perfil da estrutura das comunidades bacterianas do solo, avaliado por PCR-DGGE.

3. A adição de cama-de-frango, como agente para a biofumigação, estimula a atividade da beta-glicosidase, mas não apresenta efeito sobre a estrutura da comunidade bacteriana do solo por PCR-DGGE.

\section{Referências}

ABOIM, M.C.R.; COUTINHO, H.L.C.; PEIXOTO, R.S.; BARBOSA, J.C.; ROSADO, A.S. Soil bacterial community structure and soil quality in a slash-and-burn cultivation system in Southeastern Brazil. Applied Soil Ecology, v.38, p.100-108, 2008.

BAPTISTA, M.J.; REIS JÚNIOR, F.B.; XAVIER, G.R.; ALCÂNTARA, C.; OLIVEIRA, A.R.; SOUZA, R.B.; LOPES, C.A. Eficiência da solarização e biofumigação do solo no manejo da murcha-bacteriana do tomateiro no campo. Pesquisa Agropecuária Brasileira, v.42, p.933-938, 2007.

BARBOUR, E.K.; HUSSEINI, S.A.; FARRAN, M.T.; ITANI, D.A.; HOUALLA, R.H.; HAMADEH, S.K. Soil solarization: a sustainable agriculture approach to reduce microorganisms in chicken manuretreated soil. Journal of Sustainable Agriculture, v.19, p.95-104, 2002.
BLOK, W.J.; LAMERS, J.G.; TERMORSHUIZEM, A.J.; BOLLEN, G.J. Control of soilborne plant pathogens by incorporating fresh organic amendments followed by tarping. Phytopathology, v.90, p.253-259, 2000.

CHAER, G.M.; TÓTOLA, M.R. Impacto do manejo de resíduos orgânicos durante a reforma de plantios de eucalipto sobre indicadores de qualidade do solo. Revista Brasileira de Ciência do Solo, v.31, p.1381-1396, 2007.

DENG, S.P.; TABATABAI, M.A. Effect of tillage and residue management on enzyme activities in soils: III. Phosphatases and arylsulfatase. Biology and Fertility of Soils, v.24, p.141-146, 1997.

EMBRAPA HORTALIÇAS. Dados meteorológicos da Estação Agroclimática do CNPH. Disponível em: <http:// www.cnph.embrapa.br/cnph/consulta.html>. Acesso em: 12 dez. 2006.

FERREIRA, E.P.B.; DUSI, A.N.; XAVIER, G.R.; RUMJANEK, N.G. Rhizosphere bacterial communities of potato cultivars evaluated through PCR-DGGE profiles. Pesquisa Agropecuária Brasileira, v.43, p.605-612, 2008.

GELSOMINO, A.; CACCO, G. Compositional shifts of bacterial groups in a solarized and amended soil as determined by denaturing gradient gel electrophoresis. Soil Biology and Biochemistry, v.38, p.91-102, 2006.

GELSOMINO, A.; KEIJZER-WOLTERS, A.C.; CACCO, G.; VAN ELSAS, J.D. Assessment of bacterial community structure in soil by polymerase chain reaction and denaturing gradient gel electrophoresis. Journal of Microbiological Methods, v.38, p.1-15, 1999.

GHINI, R. Desinfestação do solo com o uso de energia solar: solarização e coletor solar. Jaguariúna: Embrapa-CNPMA, 1997. 29p. (Embrapa-CNPMA. Circular Técnica, 1).

GHINI, R.; SCHOENMAKER, I.A.S.; BETTIOL, W. Solarização do solo e incorporação de fontes de matéria orgânica no controle de Pythium spp. Pesquisa Agropecuária Brasileira, v.37, p.12531261, 2002.

HUGENHOLTZ, P.; GOEBEL, B.M.; PACE, N.R. Impact of culture-independent studies on the emerging phylogenetic view of bacterial diversity. Journal of Bacteriology, v.180, p.4765-4774, 1998.

KATAN, J.; DeVAY, J.E. Soil solarization: historical perspectives, principles and uses. In: KATAN, J.; DeVAY, J.E. (Ed.). Soil solarization. Boca Raton: CRC Press, 1991. p.23-37.

KATAN, J.; GREENBERGER, A.; ALON, H.; GRINSTEIN, A. Solar heating by polyethylene mulching for the control of diseases caused by soil-borne pathogens. Phytopathology, v.66, p.683-688, 1976.

KENNEDY, A.C. Bacterial diversity in agroecosystems. Agriculture, Ecosystems and Environment, v.74, p.65-76, 1999.

LAZAROVITS, G. Management of soil-borne plant pathogens with organic soil amendments: a disease control strategy salvaged from the past. Canadian Journal of Plant Pathology, v.23, p.1-7, 2001.

MAHMOUD, S.M. Effect of soil solarization on population densities of some soil microorganisms. Assiut Journal of Agricultural Sciences, v.27, p.93-105, 1996.

MATSUOKA, M.; MENDES, I.C.; LOUREIRO, M.F. Biomassa microbiana e atividade enzimática em solos sob vegetação nativa e 
sistemas agrícolas anuais e perenes na região de Primavera do Leste (MT). Revista Brasileira de Ciência do Solo, v.27, p.425-433, 2003.

MUYZER, G.; SMALLA, K. Application of denaturing gradient gel electrophoresis (DGGE) and temperature gradient gel electrophoresis (TGGE) in microbial ecology. Antonie Van Leeuwenhoek, v.73, p.127-141, 1998.

OKUR, N.; TÜZEL, Y.; CENGEL, M. Effect of soil solarization on the microbial population and activity in the greenhouse. In: CHOUKR-ALLAH, R. (Ed.). Protected cultivation in the Mediterranean region. Paris: CIHEAM, 1999. p.407-411.

PATRÍCIO, F.R.A.; SINIGAGLIA, C.; BARROS, B.C.; FREITAS, S.S.; TESSARIOLI NETO, J.; CANTARELLA, H.; GHINI, R. Solarization and fungicides for the control of drop, bottom rot and weeds in lettuce. Crop Protection, v.25, p.31-38, 2006.

ROHLF, F.J. NTSYS-pc: numerical taxonomy and multivariate analysis system: version 1.80. New York: Exeter Software, 1994.

SCHOENMAKER, I.A.S.; GHINI, R. Biofumigação do solo para o controle de Pythium spp. Summa Phytopathologica, p.27, p.308-312, 2001.
SCHÖNFELD, J.; GELSOMINO, A.; VAN OVERBEEK, L.S.; GORISSEN, A.; SMALLA, K.; VAN ELSAS, J.D. Effects of compost addition and simulated solarisation on the fate of Ralstonia solanacearum biovar 2 and indigenous bacteria in soil. FEMS Microbiology Ecology, v.43, p.63-74, 2003.

SHUKLA, L.; SINGH, D.K.; YADURAJU, N.T.; DAS, T.K.; MAGU, S.P. Effect of soil solarization on soil microflora and soil enzymatic activity. Annals of Plant Protection Sciences, v.8, p.218-222, 2000.

SMALLA, K.; OROS-SICHLER, M.; MILLING, A.; HEUER, H.; BAUMGARTE, S.; BECKER, R.; NEUBER, G.; KROPF, S.; ULRICH, A.; TEBBE, C.C. Bacterial diversity of soils assessed by DGGE, T-RFLP and SSCP fingerprints of PCR-amplified 16S rRNA gene fragments: do the different methods provide similar results? Journal of Microbiological Methods, v.69, p.470-479, 2007.

SOUZA, N.L. Solarização do solo. Summa Phytopathologica, v.20, p.3-15, 1994.

STAPLETON, J.J. Fumigation and solarization practice in plasticulture systems. HortTechnology, v.6, p.189-192, 1996.

STAPLETON, J.J. Soil solarization in various agricultural production systems. Crop Protection, v.19, p.837-841, 2000.

Recebido em 22 de novembro de 2007 e aprovado em 13 de junho de 2008 